\title{
Locked-In Syndrome: A Systematic Review of Long-Term Management and Prognosis
}

Taras Halan ${ }^{1}$, Juan Fernando Ortiz ${ }^{2,3}$, Dinesh Reddy ${ }^{4}$, Abbas Altamimi ${ }^{5}$, Abimbola O. Ajibowo ${ }^{6}$, Stephanie P. Fabara ${ }^{7}$

1. General Medicine, Ternopil National Medical University, Ternopil, UKR 2. Neurology, Universidad San Francisco de Quito, Quito, ECU 3. Neurology, Larkin Community Hospital, Miami, USA 4. Neurology, Mysore Medical College, Mysore, IND 5. Emergency Medicine, Amiri Hospital, Kuwait, KWT 6. Internal Medicine, University Hospitals Cleveland Medical Center, Dallas, USA 7. General Medicine, Universidad Católica de Santiago de Guayaquil, Guayaquil, ECU

Corresponding author: Juan Fernando Ortiz, sumjuanfer41@gmail.com

\begin{abstract}
Locked-in syndrome (LIS) is a neurological disorder in which there is damage to the ventral pons and caudal midbrain. An ischemic cause, such as basilar artery occlusion, can often lead to LIS. LIS has three subtypes: classical, partial, and total. There is loss of motion in the four extremities in classical LIS, loss of horizontal gaze, and aphasia. In partial LIS, the patient still has some motor function. Complete LIS has the worst outcome because patients cannot blink or have vertical gaze, thus rendering them incapable of communicating. Most cases of LIS occur due to ischemic infarcts. These patients require a great deal of physical rehabilitation to regain partial motor ability and a means to communicate. While the clinical features and pathophysiology are known, the prognosis and long-term treatment remain unknown.

We conducted a systematic review using the Meta-Analysis Of Observational Studies in Epidemiology (MOOSE) protocol. We use an advanced PubMed strategy using the inclusion criteria of observational studies or clinical trials conducted in the last 20 years, written in English, and conducted on humans. We excluded systematic reviews, literature reviews, metanalysis, and studies that did not meet the outcomes of our objectives.
\end{abstract}

The prognosis of LIS is not good, and most patients remain locked in, with poor quality of life, especially motor functions. Respiratory failure and depression are big comorbidities. In the acute setting, patients benefit from rapid intervention. The subacute treatment needs to manage aggressively to improve functional scores best. The long-term treatment focus is on the quality of life and managing comorbidities.

Review began 06/18/2021 Review ended 07/23/2021 Published 07/29/2021

\section{๑) Copyright 2021}

Halan et al. This is an open access article distributed under the terms of the Creative Commons Attribution License CC-BY 4.0., which permits unrestricted use, distribution, and reproduction in any medium, provided the original author and source are credited.
Categories: Neurology

Keywords: locked in syndrome, prognosis, long-term care, stroke, long term care

\section{Introduction And Background}

Stroke is a leading cause of disability, dementia, and death worldwide [1]. Strokes can be divided into hemorrhagic strokes and ischemic strokes [1]. Strokes can lead to brainstem syndromes. There are three subclassifications among brainstem syndromes: midbrain, pontine, and medullary syndromes. Branches of the posterior cerebral artery are involved in midbrain infarcts; the basilar artery and anterior inferior cerebral artery are involved in pons' strokes. Finally, the anterior spinal artery and the posterior inferior cerebellar artery are involved in medullary strokes [2]. In this paper, we will focus on the pontine syndrome, the locked-in syndrome (LIS).

LIS is the most dramatic presentation of a brainstem infarct in the pons [2]. Patients with LIS develop quadriplegia and feel trapped in their bodies. Patients with LIS usually conserve their conscience and can communicate by blinking. LIS syndrome is generally infrequent, but it has been described before [2]. LIS is a complex neurological disorder characterized by quadriplegia, bulbar palsy, and sensory loss [3]. In LIS, there is preserved vertical eye movement, blinking, and level of consciousness [3]. LIS can be caused by occlusion in the mid-basilar artery; it also can be caused by trauma and hemorrhages [4]. Occlusion of the mid-basilar artery results in infarction in the ventral pons but spares the pontine tegmentum [3]. LIS has subtypes: classical, partial, and total LIS.

In classical LIS, there is the characteristic loss of movement in the four extremities and anarthria. In partial LIS, the patient still has some motor function. Complete LIS has the worst outcome because, besides quadriplegia, they cannot blink or have vertical gaze, making them unable to communicate [4]. Patterson and Garbois described 139 patients with LIS; 82 had an infarction in the pons' base. The other patients had different etiologies, such as trauma, central pontine myelinolysis, tumors, encephalitis, neuro-Behcet's disease, multiple sclerosis, and other etiologies of less frequency [5].

Patients have quadriplegia because of the involvement of the corticospinal tracts [6]. The vertical gaze is 


\section{Cureus}

unaffected because of the nucleus' location in the midbrain's rostral portion [6]. Medial and lateral gaze palsies are common. They can also have diplopia and blurry vision [7] Patients with LIS seem to be unconscious and unaware of their surroundings. However, functional MRI tends to show normal activity [7]. While consciousness is impaired, there has been a report of impaired attention, executive function, and memory [4]. Respiration is often impaired in these patients when the lateral tegmentum is involved [5]. Anarthria is due to paralysis of the facial-glosso-pharyngo-laryngeal muscles and damage of the corticobulbar fibers [7]. Simultaneously, the sensory system is spared most of the time because of the sensory pathways' lateral location. However, the manifestations range from normal to absent [5]. Respiration is generally affected. These patients can present with different respirations patterns like Cheyne-Stokes, apneustic, and ataxic [5]. Table 1 shows the main clinical features of LIS.

\begin{tabular}{|lll|}
\hline Clinical features & & \\
\hline Quadriplegia & Apneustic respiratory pattern & Preserved consciousness \\
Anarthria & Emotional liability & Preserved vertical gaze and blinking \\
Normal or absent sensation & Vertigo & Lateral gaze palsy \\
Cheyne-Stokes respiratory pattern & Insomnia & Preserved hearing \\
Ataxic respiratory pattern & Internuclear ophthalmoplegia & Impaired attention and memory (early stages) \\
\hline
\end{tabular}

TABLE 1: Clinical features of locked-in syndrome

While the clinical features, diagnosis, and classification of locked-in syndrome have been established, the treatment and prognosis of this condition remain mainly unknown. We will conduct a systematic review of the prognosis and possible treatment for the rehabilitation of these patients.

\section{Review}

\section{Methods}

Search Strategy

We performed a systematic review of the prognosis and treatment of locked-in syndrome. We used the Meta-Analysis Of Observational Studies in Epidemiology (MOOSE) protocol [8-9]. We conducted a search of the last 20 years of articles related to the prognosis and treatment of locked-in syndrome using PubMed as the database for this article.

Eligibility Criteria and Study Selection

The search included any kind of articles except for literature reviews, systematic reviews, and metanalysis. We only included full papers, with humans subjects, and written in the English language. After careful examination, we only included papers with the following characteristics. 1) Population: patients with locked-in syndrome; 2) Intervention: either the quality of life, mortality, or mean years of survival; 3 : Comparator: Initial state of locked-in syndrome; 4) Outcome: either prognosis or treatment.

Data Extraction and Analysis

We extracted in each article, the author, country, and year of publication. For the methods, we analyzed the study type, the number of participants, the mean time been diagnosed with locked-in syndrome, and the etiology of the syndrome. Regarding the results, we analyzed the main outcomes of each study related to the prognosis and treatment of this condition, and we wrote the main conclusions of each study.

Bias Assessment

We used the Cochrane Collaboration risk-of-bias tool to analyzed clinical studies, and for observational studies, we used the ROBINS-I tool for observational studies [10-11].

\section{Results}

Figure 1 details the results of the study in a step-by-step manner. 


\section{Cureus}

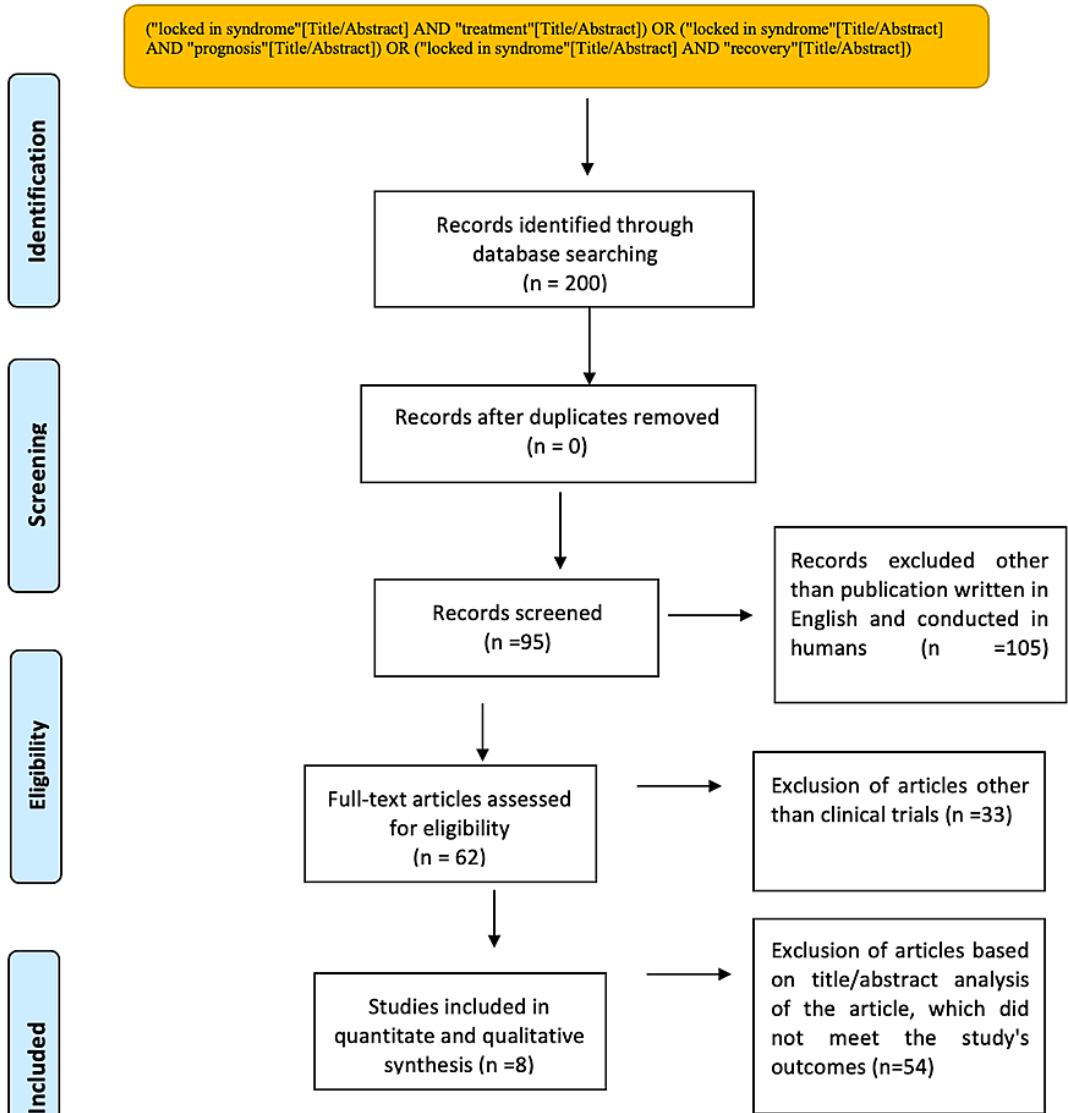

FIGURE 1: PRISMA flow chart of the systematic review

PRISMA: Preferred Reporting Items for Systematic Reviews and Meta-Analyses

Study characteristics of the prognosis of LIS [3,11-15]. 


\section{Cureus}

\begin{tabular}{|c|c|c|c|c|c|}
\hline $\begin{array}{l}\text { Author, } \\
\text { year of } \\
\text { publication }\end{array}$ & Outcome & Country & Participants & $\begin{array}{l}\text { Meantime } \\
\text { with LIS }\end{array}$ & $\begin{array}{l}\text { Etiology of } \\
\text { LIS in } \\
\text { patients }\end{array}$ \\
\hline $\begin{array}{l}\text { Sverling et } \\
\text { al, 2019 } \\
\text { [12] }\end{array}$ & Prognosis & Sweden & $7 / 10$ were men.; the mean age was 49 years. & $\begin{array}{l}\text { Meantime } \\
\text { having LIS } \\
-5.9 \\
\text { years. }\end{array}$ & $\begin{array}{l}70 \% \text { have an } \\
\text { ischemic } \\
\text { stroke. }\end{array}$ \\
\hline $\begin{array}{l}\text { Lugo et al, } \\
2015 \text { [13] }\end{array}$ & Prognosis & France & 88 participants (31 females, 57 men). Mean age 52. & $\begin{array}{l}\text { Meantime } \\
\text { having LIS } \\
-10+/-6 \\
\text { years. }\end{array}$ & $\begin{array}{l}\text { Data not } \\
\text { reported. }\end{array}$ \\
\hline $\begin{array}{l}\text { Kohnen et } \\
\text { al, } 2015 \text { [3] }\end{array}$ & Prognosis & Holland & $\begin{array}{l}187 \text { organizations were asking if they have patients with locked-in } \\
\text { syndrome. } 12 \text { were reported among all organizations. Two patients } \\
\text { have the classic locked-in syndrome. While six have partially locked- } \\
\text { in syndrome. Two patients were in a vegetative state, and two } \\
\text { patients were excluded. }\end{array}$ & $\begin{array}{l}\text { Meantime } \\
\text { having LIS } \\
\text { - } 6 \text { years. }\end{array}$ & $\begin{array}{l}\text { The majority } \\
\text { of patients } \\
\text { had an } \\
\text { ischemic } \\
\text { stroke. }\end{array}$ \\
\hline $\begin{array}{l}\text { Casanova } \\
\text { et al, [14] }\end{array}$ & Prognosis & Italy & A follow-up of five months to six years of patients with LIS. & $\begin{array}{l}\text { Average } \\
\text { time of } \\
\text { having LIS } \\
-6 \text { years. }\end{array}$ & $\begin{array}{l}\text { Etiology was } \\
\text { vascular in } \\
11 \text { cases } \\
\text { and } \\
\text { traumatic in } \\
\text { three cases. }\end{array}$ \\
\hline $\begin{array}{l}\text { Bruno et } \\
\text { al, [15] }\end{array}$ & Prognosis & Belgium & Five pediatric patients with LIS. & $\begin{array}{l}\text { Meantime } \\
\text { of having } \\
\text { LIS - } 14 \\
\text { years. }\end{array}$ & $\begin{array}{l}\text { Stroke in the } \\
\text { brainstem ( } \\
\text { Four } \\
\text { Hemorrhagic } \\
\text { and one } \\
\text { Ischemic). }\end{array}$ \\
\hline
\end{tabular}

TABLE 2: Study characteristics of the study

Table 3 shows the studies related to the long-term treatment of LIS [16-18].

\begin{tabular}{|l|l|l|l|l|}
\hline $\begin{array}{l}\text { Author, year } \\
\text { of } \\
\text { publication }\end{array}$ & Outcome & Country & Participants & Intervention \\
\hline $\begin{array}{l}\text { Sacco et al, } \\
2010[16]\end{array}$ & Treatment & Italy & $\begin{array}{l}\text { Four patients with locked-in syndrome and } \\
\text { opsoclonus-myoclonus syndrome }\end{array}$ & $\begin{array}{l}\text { Training session with psychotherapy and } \\
\text { rehabilitation. }\end{array}$ \\
$\begin{array}{l}\text { Pistola et al, } \\
2014[17]\end{array}$ & Treatment & $\begin{array}{l}\text { United } \\
\text { States }\end{array}$ & $\begin{array}{l}\text { Four patients with locked-in syndrome and } \\
\text { opsoclonus-myoclonus syndrome }\end{array}$ & Gabapentin 1200 mg. \\
\hline $\begin{array}{l}\text { Hoyer et al, } \\
2014[18]\end{array}$ & Treatment & Norway & $\begin{array}{l}\text { A case series of } 16 \text { patients with Locked-In } \\
\text { syndrome. Only nine patients participate in } \\
\text { the study. }\end{array}$ & $\begin{array}{l}\text { Rehabilitation program five times a week that } \\
\text { included physical, speech, shallow, and } \\
\text { psychological therapy. }\end{array}$ \\
\hline
\end{tabular}

TABLE 3: Study characteristics regarding the long-term treatment of LIS

LIS: locked-in syndrome

Table 4 describes the outcomes of the studies related to prognosis and long-term treatment of LIS [3,12-17]. 


\section{Cureus}

\begin{tabular}{|c|c|c|}
\hline $\begin{array}{l}\text { Author, } \\
\text { year of } \\
\text { publication }\end{array}$ & Problem & Conclusions \\
\hline $\begin{array}{l}\text { Pistola et } \\
\text { al, 2010 } \\
{[17]}\end{array}$ & $\begin{array}{l}\text { opsoclonus- } \\
\text { myoclonus } \\
\text { syndrome }\end{array}$ & $\begin{array}{l}\text { The patients improve their symptoms and their quality of life. The symptoms resolve quickly and there } \\
\text { were long-lasting. }\end{array}$ \\
\hline $\begin{array}{l}\text { Sacco et } \\
\text { al, 2010 } \\
{[16] .}\end{array}$ & $\begin{array}{l}\text { Pathological } \\
\text { laughter and } \\
\text { crying }\end{array}$ & After six to eight weeks, patients regain control of their outbursts \\
\hline $\begin{array}{l}\text { Hoyer et al, } \\
2014[18]\end{array}$ & Quality of life. & $\begin{array}{l}\text { Physical performance improved in all patients with incomplete LIS. Improvements ranged from } \\
\text { walking, practice walking, and better postural control of the head. }\end{array}$ \\
\hline $\begin{array}{l}\text { Sverling et } \\
\text { al, 2019 } \\
\text { [12] }\end{array}$ & Quality of life & $\begin{array}{l}\text { There was a decrease of mean type survival of } 1.9 \text { years. Seven patients were still alive. Three patients } \\
\text { experience a good quality of life. Mortality } 30 \% \text { Three patients experience a good quality of life. All } \\
\text { participants report having some improvement. }\end{array}$ \\
\hline $\begin{array}{l}\text { Lugo et al, } \\
2015 \text { [13] }\end{array}$ & Quality of life & $\begin{array}{l}62 \% \text { used eye communication with or without assistant technology. } 49 \% \text { use verbal communication, } \\
\text { and } 73 \% \text { of patients reported improvement of their eye movements. } 92 \% \text { of patients could establish } \\
\text { communication beyond a simple yes or no. }\end{array}$ \\
\hline $\begin{array}{l}\text { Kohnen et } \\
\text { al, } 2015[3]\end{array}$ & Quality of life & $\begin{array}{l}\text { The study looked at the prevalence and characteristics of LIS in Dutch nursing homes. No } \\
\text { indicative of the prevalence of LIS in the entire country due to factors such as patients living outside } \\
\text { nursing homes and receiving home care as well as the Dutch practice of end-of-life decision making } \\
\text { which included euthanasia or withholding or withdrawing artificial nutrition/hydration. }\end{array}$ \\
\hline $\begin{array}{l}\text { Casanova } \\
\text { et al, [14] }\end{array}$ & Quality of life & $\begin{array}{l}21 \% \text { of subjects had a motor recovery, } 28 \% \text { had verbal communication, } 42 \% \text { had swallow recovery, } \\
42 \% \text { communication through devices, effective bladder and bowel control in } 35 \% \text {, good breathing } \\
\text { patterns in } 50 \% \text {. }\end{array}$ \\
\hline $\begin{array}{l}\text { Bruno et } \\
\text { al, [15] }\end{array}$ & $\begin{array}{l}\text { Quality of life } \\
\text { and } \\
\text { Rehabilitation. }\end{array}$ & $\begin{array}{l}35 \% \text { of pediatric locked-in syndrome patients showed some motor recovery, } 26 \% \text { showed good } \\
\text { recovery, } 16 \% \text { remained quadriplegic and aphonic, and } 23 \% \text { died. }\end{array}$ \\
\hline
\end{tabular}

\section{TABLE 4: Outcomes of the studies related to prognosis and treatment of LIS}

Bias Assessment

In Table 5 we use the Robins- 1 tool to evaluate the risk in the studies regarding the prognosis and long-term treatment of LIS [3,12-17]. 


\section{Cureus}

\begin{tabular}{|c|c|c|c|c|c|c|c|}
\hline Study & Confounding & $\begin{array}{l}\text { Selection } \\
\text { bias }\end{array}$ & $\begin{array}{l}\text { Classification of } \\
\text { intervention }\end{array}$ & $\begin{array}{l}\text { Deviation from } \\
\text { intervention }\end{array}$ & $\begin{array}{l}\text { Missing } \\
\text { data }\end{array}$ & $\begin{array}{l}\text { Measurement of } \\
\text { the outcome }\end{array}$ & $\begin{array}{l}\text { Selection of } \\
\text { reported result }\end{array}$ \\
\hline $\begin{array}{l}\text { Pistola et al, } \\
2010 \text { [16] }\end{array}$ & Low & Low risk & Moderate risk & Low risk & Low risk & High risk & Low risk \\
\hline $\begin{array}{l}\text { Sacco et al, } \\
2010 \text { [16] }\end{array}$ & Low & Low risk & Moderate risk & Low risk & Low risk & High risk & Low risk \\
\hline $\begin{array}{l}\text { Hoyer et al, } 2014 \\
\text { [18] }\end{array}$ & Low & Low risk & Low risk & Low risk & Low risk & High risk & Low risk \\
\hline $\begin{array}{l}\text { Sverling et al, } \\
2019 \text { [12] }\end{array}$ & Low & Low risk & Low risk & Low risk & Low risk & Low risk & Low risk \\
\hline $\begin{array}{l}\text { Lugo et al, } 2015 \\
\text { [13] }\end{array}$ & Low & Low risk & Low risk & Low risk & Low risk & High risk & Low risk \\
\hline $\begin{array}{l}\text { Kohnen et al, } \\
2015 \text { [3] }\end{array}$ & Moderate & $\begin{array}{l}\text { Moderate } \\
\text { risk }\end{array}$ & Low risk & Low risk & $\begin{array}{l}\text { Moderate } \\
\text { risk }\end{array}$ & High risk & Low risk \\
\hline $\begin{array}{l}\text { Casanova et al, } \\
\text { [14] }\end{array}$ & Moderate & Low risk & Low risk & Low risk & $\begin{array}{l}\text { Moderate } \\
\text { risk }\end{array}$ & High risk & Low risk \\
\hline $\begin{array}{l}\text { Bruno et al, } \\
2015 \text { [15] }\end{array}$ & Low & $\begin{array}{l}\text { moderate } \\
\text { risk }\end{array}$ & Low risk & Low risk & $\begin{array}{l}\text { Moderate } \\
\text { risk }\end{array}$ & High risk & Low risk \\
\hline
\end{tabular}

TABLE 5: Bias assessment using the Robins-1 tool

Regarding confounding factors, Kohnen et al., including the inability to gather a comprehensive prevalence result due to Netherlands euthanasia or withholding/withdrawing artificial nutrition and hydration in the context of end-of-life decision-making. Additionally, no prevalence comparison was done due to the fact that prevalence data were not available in the literature [3].

In the Casanova et al. study, the evaluation of prognosis and recovery in patients with LIS receiving early intensive rehabilitation care is somewhat confounded given the widely skewed data and the chronological order of the care administered to patients diagnosed with LIS [14].

\section{Discussion}

Prognosis

Patients usually do not have a complete recovery. Despite this, the view on prognosis and mortality has drastically improved over the years, yielding positive results [12]. If the patient is medically stabilized and survives the first year where $87 \%$ of the deaths occur within the first four months, five-year survival can reach $86 \%$ [12]. The survival rate after the 10 -year mark of onset is reported to be around $80 \%$ [8]. Most of the patients with LIS become dependent on others to carry out activities of daily living due to highly impaired motor function. Studies on quality of life (QoL) have shown that the majority of low scores on QoL stem from motor impairment as opposed to other cognitive/mental reasons. This is not to say that patients with LIS do not suffer from depression or other psychiatric ailments. Mild and moderate depression is more common in patients with LIS than in healthy controls.

Emotional volatility has been documented in such patients and manifests in the form of involuntary laughing or crying, a known problem after injuries to the brainstem [12]. Initial attention span and ability to communicate are affected. However, patients tend to improve with time [8]. Another report of 139 patients demonstrated a mortality rate of $60 \%$ in patients with LIS [6]. Most patients continue to be locked in or have significant impairments such as memory loss seen in $18 \%$ of the patients [8]. However, cases of partial recovery have been detailed in the literature [18]. A highly complex, as well as significantly prolonged in comparison to the average stroke rehab program, daily inpatient rehabilitation program consisting of occupational, physical, and speech therapy has been shown effective in dramatically increasing the patient's Freedom Independent Movement (FIM) score as well as provide the ability to complete most activities of daily living (ADLs) with minimal assistance [19]. Pulmonary complications, such as atelectasis and pneumonia, due to aspiration and impaired cough reflex are the leading cause of death in patients with LIS [8].

Patients' families and their needs have to be taken into account as well. One of the most important needs 
that have been reported by patients' relatives was the need for medical information. Of the multitude of topics that related to taking care of the patients, the most important was for LIS' family members to know that the patient's needs and wishes were respected by the medical staff. A goal of care form should be signed by the guardian if the patient has does not have one signed previously. Discuss with the family the goal of care if there is one in place by the patient before getting ill, and if not, the person in charge of the guardian should outline the goal of care to the medical team. Receiving accurate medical information is of crucial importance to families of patients with LIS and their quality of life seems to be directly correlated [13].

A Dutch study has shown the very low prevalence of LIS in nursing homes. However, this may stem from two reasons that are somewhat unique to the Netherlands. One reason is that patients with LIS may be receiving home care outside the nursing homes due to the government budget allowance. Another reason is the Dutch end-of-life decision-making, such as euthanasia or withdrawing artificial nutrition/hydration, which decreases the prevalence of patients with LIS [3].

Regarding prognosis in children, blockage of the basilar artery is known to be poor, with a death rate of $25 \%$ and severe complications in survivors. However, compared to adult patients, the death rate for vascular etiology is over $75 \%$. Which suggests younger patients have a better prognosis [15]. The prognosis in the same compared to adults was better. Most of the children with LIS show some motor recovery (35\%). In $26 \%$ of cases, the patient returned to independent living; $16 \%$ remained quadriplegic, and $23 \%$ died [15].

\section{Long-Term Treatment}

Multidisciplinary rehabilitation is the cornerstone treatment of locked-in syndrome. It includes physical, speech, and occupational therapy and assistive devices to get more functional improvement. Also, the treatment could be divided into two categories: immediate and long-term management. In acute settings of LIS, securing the airway and providing sufficient oxygenation is the first step as well as a critical component of acute care [14]. In the acute setting of patients with LIS secondary to ischemic stroke of vertebral or basilar arteries, it is necessary to provide recanalization through intravenous or intraarterial thrombolysis within 48 hours of the onset of symptoms [20].

In terms of subacute and long-term therapies, LIS treatment is aimed to give aggressive supportive measures such as physical, speech, respiratory, swallowing therapy, and as mentioned above, the use of assisted devices. One multidisciplinary rehabilitation study in 2003 aimed at the recovery outcomes of 14 patients. It showed the following data. Three patients gained partial or full independence in daily living activities; six patients were able to swallow completely; four patients recovered verbal communication; six patients were able to use their hands and made finger or head movements, and tracheostomy was removed by six patients [14].

It is imperative that early and intensive multidisciplinary rehabilitation be started within a mean of one month after the onset of the morbid results. According to Casanova's study, this leads to a significantly lower mortality rate, more significant motor recovery, complete swallow recovery, verbal communication, communication through medical devices, and effective bowel and bladder control [14].

The combination of early use, proper goal setting, and multimodal treatments that are frequent and sensory can provide significant improvement in the treatment of patients with LIS. Any and all resources should be utilized to treat the LIS population. Functional electrical stimulation (FES) cycling or a two-

channel neuromuscular electrical stimulation (NMES) unit utilizing the principles of neuromuscular reeducation paired with repetitive task practice have been found particularly beneficial. Paired with locomotor training, or body-weight supported treadmill training (BWSTT), utilizing the LiteGait harness (LiteGait, Tempe, Arizona) over the treadmill and overground has proven particularly useful for lower extremity therapy. Robot-assisted gait training (RAGT) improves lower limb function, functional ambulation, as well as independence [17].

Upper extremity training utilizing limb robotics, such as the Armeo ${ }^{\circledR}$ Spring program (Hocoma AG, Volketswil, Switzerland), has shown efficacy in increasing accuracy and time of initiation. The repetitive task practice combined with constant visual feedback results in an improvement in self-monitoring, upper limb motor function, automatic motor responses, and sensory feedback patterns. Extremity neuroprosthesis, such as Bioness H200, can be used for functional recovery of grasp in upper extremities, as well as facilitate functional arm use, spasticity reduction, grip strength, and active range of motion [17].

Motor function and postural control improvement in patients with incomplete LIS can be enhanced with the aid of treadmill therapy (TT). TT is a safe and adverse effect-free method that has demonstrated improved physical performance through body weight support assistance in which physical therapists assisted LIS patients with incremental passive movements, which later progressed to more independent body support, which have shown efficacious in postural trunk support, lower extremity mobility, and head control [17].

Regarding LIS complication management, it is essential to monitor respiratory secretions to prevent pneumonia, which is the leading cause of death. These measures include chest physiotherapy and breathing 
exercises [14].

Bruno et al. conclude that early and intensive rehabilitation can help with verbal communication and functional motor outcomes regarding long-term management in young children. Several studies have found that cognitive abilities are unaffected in the case of a locked-in syndrome in young people caused by a single brainstem lesion. In contrast, individuals with multiple lesions may experience cognitive dysfunction.

Treatments that depend on brain plasticity are expected to be more useful in early life as compared to adults [15].

Speech-language and music therapy co-treatment showed improvements in voice output, initiation, as well as coordination. VitalStim using NMES with a speech therapist not only increases airway clearance but it also advances diet status from NPO to puree solids with ice chips. Eye gaze selection can be used for initial communication that later can progress to the Verbally app for functional communication if hand movement is to return [21].

Regarding communication treatment in LIS cases that have been complicated by opsoclonus-myoclonus, gabapentin showed extremely promising results. Opsoclonus-myoclonus is a condition in which the eyes seemingly randomly and involuntarily move rapidly in the horizontal, vertical, and diagonal directions [17]. This makes communications extremely difficult, if not impossible, for patients relying on eye communication. One study noted that the administration of gabapentin resulted in rapid and long-lasting resolution of myoclonus-opsoclonus without any adverse effects by reversing opsoclonus symptoms by acting as a regulator of the saccadic circuit's gain; it might exert its effect either by enhancing pause neurons or by hindering the burst ones [17].

Among many treatment approaches, one particular focus has to be lent to the instance of pathological laughter and crying (PLC). PLC, not having any relation to any mood disorders, is hypothesized to be due to direct damage to the pontine center or an alteration in the pinto-cerebellar pathway linked to emotional behavior to contextual information. Pharmacological treatment with antidepressants has not shown concrete results. However, cognitive behavior may speed up or improve any possibility of spontaneous recovery in six to eight weeks [16].

Overall early intervention and the quality of long-term treatment make a difference in patients with LIS.

\section{Conclusions}

On average, patients with LIS syndrome have a poor prognosis, and most patients remain locked in, regaining a small amount of capacity. QoL scores remain low through the years, especially regarding the motor aspect. Depression is also a long-term complication of patients with LIS. Overall, children with LIS have a better prognosis than adults.

Multidisciplinary rehabilitation is the cornerstone of the rehabilitation of LIS. In the acute setting, rapid intervention is key for long-term prognosis. In the subacute setting, aggressive measures with speech, physical, respiratory, and swallowing need to be undertaking. Long-term therapy includes managing the quality of life and preventing comorbidities. As time progresses, regaining independence is more difficult for LIS patients. Speech therapy, respiratory therapy, visual stimulation, and music therapy are some of the long-term therapies included in the long-term care of the patients.

\section{Additional Information}

\section{Disclosures}

Conflicts of interest: In compliance with the ICMJE uniform disclosure form, all authors declare the following: Payment/services info: All authors have declared that no financial support was received from any organization for the submitted work. Financial relationships: All authors have declared that they have no financial relationships at present or within the previous three years with any organizations that might have an interest in the submitted work. Other relationships: All authors have declared that there are no other relationships or activities that could appear to have influenced the submitted work.

\section{References}

1. Ortiz JF, Ruxmohan S, Saxena A, et al.: Minocycline and magnesium as neuroprotective agents for ischemic stroke: a systematic review. Cureus. 2020, 12:e12339. 10.7759/cureus.12339

2. Ortiz de Mendivil A, Alcalá-Galiano A, Ochoa M, Salvador E, Millán JM: Brainstem stroke: anatomy, clinical and radiological findings. Semin Ultrasound CT MR. 2013, 34:131-41. 10.1053/j.sult.2013.01.004

3. Kohnen RF, Lavrijsen JC, Bor JH, Koopmans RT: The prevalence and characteristics of patients with classic locked-in syndrome in Dutch nursing homes. J Neurol. 2013, 260:1527-34. 10.1007/s00415-012-6821-y

4. Raibagkar P, Chavali RV, Kaplan TB, Kim JA, Nitka MV, Chou SH, Edlow BL: Reverse locked-in syndrome. Neurocrit Care. 2017, 27:108-14. 10.1007/s12028-017-0391-x

5. Papadopoulou SL, Dionyssiotis Y, Krikonis K, Lagopati N, Kamenov I, Markoula S: Therapeutic approaches in locked-in syndrome. Folia Med (Plovdiv). 2019, 61:343-51. 10.3897/folmed.61.e39425 
6. Patterson JR, Grabois M: Locked-in syndrome: a review of 139 cases . Stroke. 1986, 17:758-64. 10.1161/01.str.17.4.758

7. Yokose M, Furuya K, Suzuki M, et al.: Vertical gaze palsy caused by selective unilateral rostral midbrain infarction. Neuroophthalmology. 2018, 42:309-11. 10.1080/01658107.2017.1401092

8. Smith E, Delargy M: Locked-in syndrome. BMJ. 2005, 330:406-9. 10.1136/bmj.330.7488.406

9. Moher D, Liberati A, Tetzlaff J, Altman DG: Preferred reporting items for systematic reviews and metaanalyses: the PRISMA statement. PLoS Med. 2009, 6:e1000097. 10.1371/journal.pmed.1000097

10. Higgins JP, Altman DG, Gøtzsche PC, et al.: The Cochrane Collaboration's tool for assessing risk of bias in randomised trials. BMJ. 2011, 343:d5928. 10.1136/bmj.d5928

11. Sterne JA, Hernán MA, Reeves BC, et al.: ROBINS-I: a tool for assessing risk of bias in non-randomised studies of interventions. BMJ. 2016, 355:i4919. 10.1136/bmj.i4919

12. Svernling K, Törnbom M, Nordin Å, Sunnerhagen KS: Locked-in syndrome in Sweden, an explorative study of persons who underwent rehabilitation: a cohort study. BMJ Open. 2019, 9:e023185. 10.1136/bmjopen2018-023185

13. Lugo ZR, Bruno MA, Gosseries O, et al.: Beyond the gaze: communicating in chronic locked-in syndrome . Brain Inj. 2015, 29:1056-61. 10.3109/02699052.2015.1004750

14. Casanova E, Lazzari RE, Lotta S, Mazzucchi A: Locked-in syndrome: improvement in the prognosis after an early intensive multidisciplinary rehabilitation. Arch Phys Med Rehabil. 2003, 84:862-7. 10.1016/s00039993(03)00008-x

15. Bruno MA, Schnakers C, Damas F, et al.: Locked-in syndrome in children: report of five cases and review of the literature. Pediatr Neurol. 2009, 41:237-46. 10.1016/j.pediatrneurol.2009.05.001

16. Sacco S, Sarà M, Pistoia F, Conson M, Albertini G, Carolei A: Management of pathologic laughter and crying in patients with locked-in syndrome: a report of 4 cases. Arch Phys Med Rehabil. 2008, 89:775-8. 10.1016/j.apmr.2007.09.032

17. Pistoia F, Conson M, Sarà M: Opsoclonus-myoclonus syndrome in patients with locked-in syndrome: a therapeutic porthole with gabapentin. Mayo Clin Proc. 2010, 85:527-31. 10.4065/mcp.2010.0042

18. Høyer E, Normann B, Sørsdal R, Strand LI: Rehabilitation including treadmill therapy for patients with incomplete locked-in syndrome after stroke; a case series study of motor recovery. Brain Inj. 2010, 24:34-45. 10.3109/02699050903471805

19. Khurana RK, Genut AA, Yannakakis GD: Locked-in syndrome with recovery. Ann Neurol. 1980, 8:439-41. 10.1002/ana.410080418

20. Johnson TM, Romero CS, Smith AT: Locked-in syndrome responding to thrombolytic therapy. Am J Emerg Med. 2018, 36:1928.e5-7. 10.1016/j.ajem.2018.07.003

21. McNair K, Lutjen M, Langhamer K, Nieves J, Hreha K: Comprehensive, technology-based, team approach for a patient with locked-in syndrome: a case report of improved function \& quality of life. Assist Technol. 2019, 31:53-8. 10.1080/10400435.2017.1352052 